\title{
Formas de cobre em solos de vinhedos em função do pH e da adição de cama-de-frango
}

\author{
Gilmar Ribeiro Nachtigall(1), Roberta Corrêa Nogueirol(2) e Luís Reynaldo Ferracciú Alleoni(2)
}

\begin{abstract}
(1)Embrapa Uva e Vinho, Caixa Postal 130, CEP 95700-000 Bento Gonçalves, RS. E-mail: gilmar@cnpuv.embrapa.br (2)Escola Superior de Agricultura Luiz de Queiroz, Dep. de Ciência do Solo, Caixa Postal 09, CEP 13418-900 Piracicaba, SP. E-mail: rcnoguei@esalq.usp.br, Irfalleo@esalq.usp.br
\end{abstract}

Resumo - O trabalho teve como objetivo avaliar a distribuição de formas de cobre, em função do $\mathrm{pH}$ e da adição de cama-de-frango, em amostras da camada superficial $(0$ a $10 \mathrm{~cm})$ de um Neossolo Litólico distrófico típico e de um Cambissolo Húmico alumínico típico, da região da Serra Gaúcha, cultivados por mais de 15 anos com parreirais que receberam aplicações sucessivas de produtos fitossanitários à base de cobre. Para avaliar os efeitos da variação do $\mathrm{pH}$ e do teor de matéria orgânica do solo nas formas de cobre, cinco doses de $\mathrm{HNO}_{3}(50,100,200,300$ e $\left.400 \mathrm{mmol} \mathrm{kg}^{-1}\right)$ e quatro doses de cama-de-frango em base seca (10, 20, 40 e $\left.80 \mathrm{t} \mathrm{ha}^{-1}\right)$ foram adicionadas aos solos. As frações observadas foram: trocável; ligada à matéria orgânica; ligada a óxidos de $\mathrm{Fe}$, de $\mathrm{Al}$ e de $\mathrm{Mn}$; $\mathrm{e}$ fração residual. A maior proporção do cobre dos solos esteve ligada à fração orgânica (entre 70 e $80 \%$ ). Com a diminuição do pH (de 6,8 para 3,8), os teores de cobre trocável aumentaram, enquanto os teores de cobre ligados às frações matéria orgânica, óxidos e residual diminuíram. A adição de cama-de-frango não afetou significativamente a distribuição das formas de cobre nos solos, com exceção dos teores trocáveis.

Termos para indexação: parreiral, extração seqüencial, fracionamento, matéria orgânica do solo.

\section{Forms of copper in vineyard soils as affected by $\mathrm{pH}$ and poultry litter application}

\begin{abstract}
The objective of this study was to evaluate the distribution of forms of copper as affected by $\mathrm{pH}$ and poultry litter addition in samples of surface layers $(0$ to $10 \mathrm{~cm})$ of a Dystrophic Lithic Udorthent and a Humic Dystrudept, both from Serra Gaúcha (Rio Grande do Sul highlands), Brazil, cultivated for more than 15 years with vines treated with successive applications of copper-based products. To evaluate the effects of $\mathrm{pH}$ variation and soil organic matter content in copper forms, five doses of $\mathrm{HNO}_{3}\left(50,100,200,300 \mathrm{e} 400 \mathrm{mmol} \mathrm{kg}^{-1}\right)$ and four doses of poultry litter in dry basis $\left(10,20,40 \mathrm{e} 80 \mathrm{t} \mathrm{ha}^{-1}\right)$ were added to the soils. The following fractions were evaluated: exchangeable; bound to organic matter; bound to Fe, Al, and Mn oxides; and residual. The largest proportion of copper of the soil was bound to organic matter fraction (from 70 to $80 \%$ ). As the $\mathrm{pH}$ decreased from 6.8 to 3.8 , the copper exchangeable contents increased, while copper bound to organic matter, oxides, and residual fractions decreased. The application of poultry litter did not significantly affect the distribution of forms of copper in both soils, except for the exchangeable fraction.
\end{abstract}

Index terms: vineyards, sequential extraction, fractionation, soil organic matter.

\section{Introdução}

O uso de fungicidas cúpricos no controle de doenças de videiras, por vários anos, tem levado ao acúmulo do cobre na superfície do solo (Deluisa et al., 1996; Flores Vélez et al., 1996; Nogueirol et al., 2005). Uma porção significativa do cobre que atinge o solo via fungicidas, biossólidos, lodos de estações de tratamento de água ou outros resíduos permanece nas camadas mais superficiais ligada, principalmente, à matéria orgânica do solo (MO) (Brun et al., 1998; Oliveira et al., 2005; Teixeira et al., 2005).
Solos minerais e orgânicos podem adsorver metais com diferentes intensidades. A matéria orgânica do solo, os óxi-hidróxidos de $\mathrm{Fe}$ e de $\mathrm{Al}$ e os minerais de argila são os principais componentes dos solos que influenciam as reações de adsorção dos metais (Barry et al., 1995). $\mathrm{O}$ pH do solo controla a dinâmica da maioria dos metais pesados catiônicos, uma vez que a disponibilidade destes é relativamente baixa em valores de $\mathrm{pH}$ na faixa de 6,5 a 7 (Kabata-Pendias \& Pendias, 1987).

Compostos orgânicos vêm sendo usados para melhorar a fertilidade e reduzir a erosão dos solos de vinhedos na Europa. No Brasil, esta técnica de manejo 
também é utilizada; na região da Serra Gaúcha, por exemplo, a aplicação de cama-de-frango tem uso freqüente. Tais compostos podem modificar a retenção e a distribuição de cobre, em solos que recebem aplicações anuais de produtos fitossanitários, além de limitar a erosão e dispersão do metal nos ambientes de vinhedos e, particularmente, nas águas superficiais (Besnard et al., 2001).

A quantidade total de metais no solo é distribuída em frações, e eles podem estar presentes como íons livres, como complexos organo-minerais solúveis ou adsorvidos às partículas do solo. A extração seqüencial tem como principal objetivo medir, seletivamente, a distribuição de metais em solos e sedimentos (Shannon \& White, 1991). Os reagentes, o tempo de extração e a relação entre solo e solução, utilizados na extração seqüencial, são selecionados com o objetivo de solubilizar frações específicas da fase sólida, com o mínimo de interferência nas demais frações. Apesar de existirem críticas aos métodos de extração seqüiencial de metais, sobretudo relacionadas à possibilidade de readsorção e redistribuição de metais durante a extração, esse método possibilita a comparação das quantidades dos metais ligados a frações similares sob o ponto de vista químico (Candelaria \& Chang, 1997).

Pela extração seqüencial, é possível determinar o conteúdo de elementos presentes em diferentes frações e, com estudos de correlações, saber qual está mais correlacionada às quantidades extraídas por extratores químicos, bem como sua disponibilidade para as plantas (Shuman, 1986). Contudo, o predomínio do cobre em uma ou outra fração é bastante variável em razão do tipo de solo, conforme se observa nos trabalhos de Silveira et al. (2006), que verificaram que maior parte do cobre esteve ligado às frações residual e óxidos, em dois latossolos do Estado de São Paulo, e nos trabalhos de Moreira (2003), que encontrou maior quantidade de cobre na fração residual de um Latossolo Vermelho, seguida da fração óxidos e orgânica.

O objetivo deste estudo foi avaliar a distribuição das formas de cobre no solo, em função da variação do $\mathrm{pH}$ e da adição de cama-de-frango, em um Neossolo Litólico distrófico típico e em um Cambissolo Húmico alumínico típico, solos representativos da região da Serra Gaúcha, que receberam aplicações sucessivas de produtos à base de cobre, principalmente calda bordaleza.

\section{Material e Métodos}

O trabalho foi realizado com amostras da camada superficial $(0$ a $10 \mathrm{~cm})$ de um Neossolo Litólico distrófico típico (RLd) e de um Cambissolo Húmico alumínico típico
(CHa), coletados em propriedades no Município de Bento Gonçalves (29¹0'17"S e 51'31'9"W), na região da Serra Gaúcha. Esses solos foram cultivados, por mais de 15 anos, com parreirais (cultivar Isabel) que receberam aplicações sucessivas de produtos fitossanitários à base de cobre, principalmente de cobre metálico e calda bordaleza (aproximadamente dez aplicações por ano, que aportaram ao parreiral entre 30 e $65 \mathrm{~kg} \mathrm{ha}^{-1} \mathrm{de} \mathrm{Cu}$ por ano).

Antes da instalação dos experimentos, as amostras dos solos foram submetidas a análises químicas (Camargo et al., 1986), em que os valores de atributos químicos do RLd e do CHa foram, respectivamente: $\mathrm{pH}$ em $\mathrm{CaCl}_{2}$ $0,01 \mathrm{~mol} \mathrm{~L}^{-1}$ de 6,9 e 6,$4 ; \mathrm{MO}$ de 85 e $94 \mathrm{~g} \mathrm{~kg}^{-1} ; 140$ e $170 \mathrm{mmol}_{\mathrm{c}} \mathrm{dm}^{-3} \mathrm{de} \mathrm{Ca} ; 35$ e $39 \mathrm{mmol}_{\mathrm{c}} \mathrm{dm}^{-3} \mathrm{de} \mathrm{Mg} ; 5,4 \mathrm{e}$

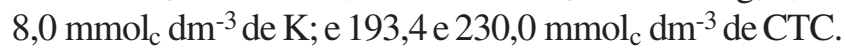
Estes solos possuíam alto teor de cobre solúvel em DPTA pH 7,3 (522 e $475 \mathrm{mg} \mathrm{kg}^{-1}$, no RLd e CHa, respectivamente).

Em amostras naturais (sem incubação) foram analisados os teores de óxidos de ferro, de alumínio e de manganês, após ataque com ácido sulfúrico, e o teor de óxido de silício por ataque alcalino; os teores de ferro livre (extraídos com ditionito-citratobicarbonato de sódio) e teores de ferro e de alumínio amorfos (extraídos com oxalato de amônio), conforme Camargo et al. (1986). Foi avaliado, também, o grau de humificação da MO dos solos, por meio de extração e do fracionamento químico das substâncias húmicas, segundo o método modificado da International Humic Substances Society (Novotny, 2002), em que a análise espectroscópica é realizada por ressonância paramagnética eletrônica (RPE). Utilizou-se, para a RPE, um espectrômetro Brukert, Banda X (9 GHz), sem o emprego de "spin trapping", para a quantificação da concentração dos radicais livres do tipo semiquinona.

Para avaliar o efeito da variação do $\mathrm{pH}$, foram adicionados aos solos 50, 100, 200, 300 e $400 \mathrm{mmol} \mathrm{kg}^{-1}$ de ácido nítrico. Amostras de $1 \mathrm{~kg}$ de solo, passadas em peneira com malha igual a 10 mesh, foram incubadas em recipientes de plástico, em umidade próxima à da capacidade máxima de retenção de água, até não se observar mais variação dos valores de $\mathrm{pH}$, o que foi obtido após 90 dias, aproximadamente.

Em outro experimento, foram aplicadas doses de 10, 20, 40 e 80 tha $^{-1}$ de cama-de-frango (em base seca), em amostras de um quilograma, passadas em peneira com malha igual a 10 mesh, além da testemunha (sem cama-de-frango). 
As amostras foram incubadas por três meses, com umidade próxima à capacidade máxima de retenção de água. A cama-de-frango utilizada, semelhante à aplicada aos parreirais, foi analisada antes da instalação do experimento, conforme Camargo et al. (1986), e apresentou os seguintes atributos químicos: relação $\mathrm{C} / \mathrm{N}$ de 15/1; $609 \mathrm{~g} \mathrm{~kg}^{-1}$ de matéria orgânica; e teores totais de $518 \mathrm{mg} \mathrm{kg}^{-1} \mathrm{de} \mathrm{Cu}, 437 \mathrm{mg} \mathrm{kg}^{-1}$ de Mn, $513 \mathrm{mg} \mathrm{kg}^{-1}$ de Zn e $4239 \mathrm{mg} \mathrm{kg}^{-1}$ de Fe. A utilização de cama-de-frango, mesmo com altos teores de cobre, se justifica pelo fato de tratar-se de material utilizado com frequiência pelos agricultores da região. Após as incubações, as amostras foram secadas em estufa a $45^{\circ} \mathrm{C}$, moídas e passadas em peneira com malha igual a 10 mesh. Para a realização da extração seqüencial, as amostras foram moídas e passadas em peneira com malha igual a 100 mesh.

Considerando-se que existe variação quanto à distribuição do cobre, nas diferentes frações obtidas pela extração sequiencial, que pode ser atribuída às diferenças entre solos quanto ao teor de óxidos no solo e quanto ao grau de humificação e teor de MO, optou-se por quantificar estas variáveis nos dois solos estudados.

A extração seqüencial do cobre foi realizada com base nos métodos utilizados por Moreira (2003) e por Silveira et al. (2006), e a fração trocável foi obtida segundo Ahnstrom \& Parker (1999), após extração com 15 mL de nitrato de estrôncio $0,1 \mathrm{~mol} \mathrm{~L}^{-1}$. Após a obtenção da fração trocável, foi obtida a fração ligada à matéria orgânica, com $5 \mathrm{~mL}$ de hipoclorito de sódio a $5 \%$, e pH ajustado a 8,5. A fração ligada aos óxidos foi obtida com uso do oxalato de amônio $0,2 \mathrm{~mol} \mathrm{~L}^{-1}+$ ácido oxálico 0,2 $\mathrm{mol} \mathrm{L}^{-1}+$ ácido ascórbico $0,1 \mathrm{~mol} \mathrm{~L}^{-1}$, ajustado a pH 3 (Schwertmann, 1964). A fração residual, que representa o teor de cobre não captado nas frações anteriores, foi obtida após digestão total com ácido nítrico + ácido fluorídrico + água deionizada, em forno de microondas, de acordo com o método do EPA 3052 (Estados Unidos, 1996).
Entre cada extração sucessiva (duas réplicas de laboratório), as amostras foram suspensas com $5 \mathrm{~mL}$ de cloreto de sódio $0,1 \mathrm{~mol} \mathrm{~L}^{-1}$, a fim de se deslocar a solução anterior que eventualmente tivesse permanecido no tubo, para reduzir a dispersão da amostra e para limitar a readsorção do metal (Ahnstrom \& Parker, 1999). Todas as suspensões foram centrifugadas a $1.225 \mathrm{~g}$ por $10 \mathrm{~min}$ e passadas em filtro de malha 10 mesh. Os extratos das frações trocável e ligada à matéria orgânica foram acidificados a $1 \%$ com ácido nítrico; nos extratos da fração ligada aos óxidos foi adicionada uma gota de tolueno, para evitar o crescimento de microrganismos Os teores de cobre foram determinados, em cada fração, por espectrometria de absorção atômica.

Os dois experimentos foram realizados em laboratório, conduzidos em delineamento inteiramente casualizado, com quatro repetições. Os resultados qualitativos foram submetidos à análise de variância e, quando os efeitos foram significativos, utilizou-se o teste de comparação de médias DMS, tendo-se tomado por base os níveis de significância maiores que $95 \%$. Os resultados quantitativos, quando da significância dos efeitos apontados pela análise de variância, foram ajustados em equações de regressão. Para a escolha das equações, foram testados os modelos linear e quadrático pelo teste $\mathrm{F}$, tendo-se escolhido aquele com significância maior que $95 \%$ e, no caso dos dois serem significativos, optou-se pelo modelo de maior grau.

\section{Resultados e Discussão}

Os teores dos óxidos e os valores de Ki das amostras naturais (sem incubação) foram semelhantes (Tabela 1), o que indica que as amostras avaliadas apresentam pequena variabilidade no grau de intemperismo. A concentração de radicais livres semiquinona expressa o grau de humificação dos ácidos húmicos; quanto maior é o grau de humificação, maior é a concentração de

Tabela 1. Teores de óxidos de ferro, alumínio e manganês após ataque com ácido sulfúrico e o teor de $\mathrm{SiO}_{2}$ por ataque alcalino; teores de ferro livre e teores de ferro e alumínio amorfos, em um Neossolo Litólico distrófico típico (RLd) e em um Cambissolo Húmico alumínico típico (CHa) da região da Serra Gaúcha, cultivados por mais de 15 anos com parreirais que receberam aplicações sucessivas de produtos à base de cobre.

\begin{tabular}{|c|c|c|c|c|c|c|c|c|c|}
\hline \multirow[t]{2}{*}{ Solo } & \multicolumn{6}{|c|}{ Ataque sulfúrico e alcalino } & \multirow{2}{*}{$\begin{array}{c}\text { Forma livre } \\
\mathrm{Fe}_{2} \mathrm{O}_{3}\end{array}$} & \multicolumn{2}{|c|}{ Forma amorfa } \\
\hline & $\mathrm{SiO}_{2}$ & $\mathrm{Al}_{2} \mathrm{O}_{3}$ & $\mathrm{Fe}_{2} \mathrm{O}_{3}$ & $\mathrm{MnO}$ & $\mathrm{K}_{\mathrm{i}}$ & $\mathrm{K}_{\mathrm{r}}$ & & $\mathrm{Fe}_{2} \mathrm{O}_{3}$ & $\mathrm{Mn}_{2} \mathrm{O}_{3}$ \\
\hline & 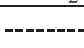 & ------1 & -1) ------ & - & & & 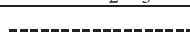 & $\left.\mathrm{kg}^{-1}\right)-$ & --------- \\
\hline RLd & 123 & 71 & 75 & 2,3 & 3,0 & 3,4 & 32,0 & 8,4 & 2,1 \\
\hline $\mathrm{CHa}$ & 145 & 65 & 78 & 2,3 & 3,8 & 4,3 & 29,1 & 8,4 & 2,3 \\
\hline
\end{tabular}


radicais livres semiquinona (Martin-Neto et al., 1998; Bayer et al., 2000). As concentrações dos radicais livres semiquinona dos ácidos húmicos (AH), do RLd e do $\mathrm{CHa}$, apresentaram resultados similares (Figura $1 \mathrm{~A}$ ), cujos valores foram próximos aos encontrados por Bayer et al. (2000), em um solo Podzólico Vermelho, do Rio Grande do Sul, e por Martin-Neto et al. (1998), em solos do Pampa Argentino. Os espectros de RPE das amostras de AH também foram muito similares (Figura $1 \mathrm{~B} \mathrm{e} \mathrm{C}$ ), com concentração do radical livre orgânico, tipo semiquinona, na faixa de g 2,003, proporcional ao grau de humificação das substâncias húmicas (Novotny \& Martin-Neto, 2002). Estes resultados indicam que os dois solos apresentam o mesmo grau de humificação da MO.

A concentração dos radicais nos solos, neste trabalho, foi inferior à observada por Cambri (2004), em dois Latossolos de Mato Grosso e um Nitossolo de São Paulo, e similar ao encontrado por esse autor para um Latossolo do Paraná. Segundo Cambri (2004), o menor grau de humificação da MO dos solos de Mato Grosso e São Paulo, em relação ao solo do Paraná, estava relacionado à menor taxa de adição de carbono orgânico e às temperaturas maiores durante $\mathrm{o}$ ano, que aumentaram as perdas de $\mathrm{C}$ nos solos de Mato Grosso e de São Paulo. Dessa forma, os dois solos devem apresentar o mesmo comportamento quanto às reações de adsorção do cobre, para condições naturais, já que possuem valores semelhantes para teores de óxidos e grau de humificação.

No experimento de variação do $\mathrm{pH}$ do solo, os teores de cobre na fração trocável aumentaram, enquanto os teores de cobre ligados às frações orgânica, óxidos e residual diminuíram (Figura 2), com a redução no $\mathrm{pH}$, em ambos os solos. Casagrande et al. (2004), num estudo de adsorção e dessorção de cobre, num Latossolo Vermelho acriférrico, também observaram efeito do $\mathrm{pH}$ na retenção de cobre e disponibilização do elemento para a solução do solo. $\mathrm{O}$ pH dos solos é, na maioria das vezes, o principal fator de controle de biodisponibilidade de cobre para plantas, uma vez que o elemento fica indisponível às plantas, em valores de pH próximos da neutralidade. Em solos ácidos, com o aumento do $\mathrm{pH}$, a densidade de sítios de adsorção para esse metal aumenta, o que reduz sua disponibilidade para as plantas (Alloway, 1990). A redução nos teores de cobre, com a redução do $\mathrm{pH}$ do solo, verificada para as frações orgânica, óxidos e residual, está relacionada à liberação do cobre adsorvido a esses constituintes do solo.
Tanto no RLd quanto no CHa, a maior proporção do cobre (entre 70 e $80 \%$ ) estava ligada à fração orgânica
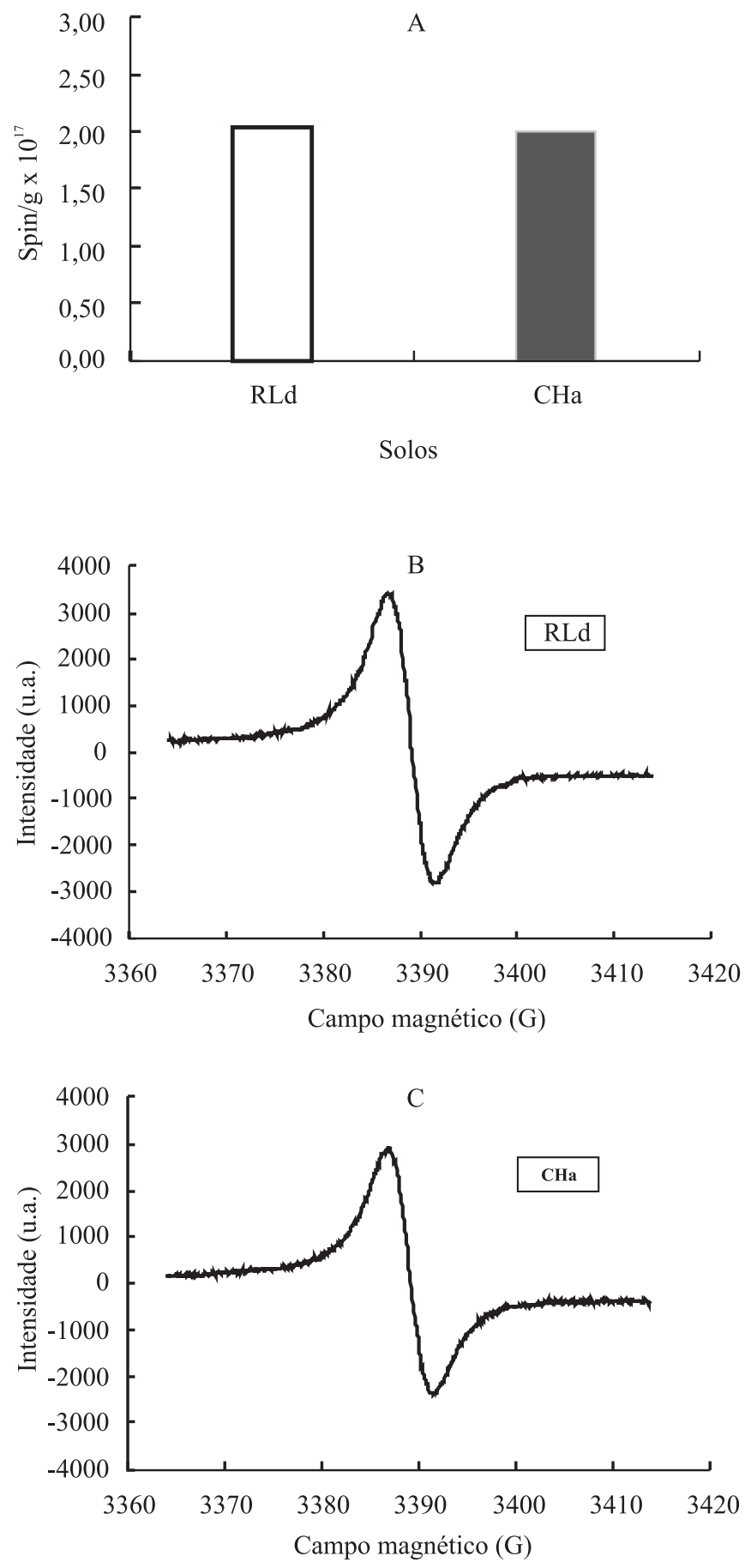

Figura 1. Concentração dos radicais livres semiquinona dos ácidos húmicos (A) e espectros de ressonânica paramagnética eletrônica (B e C), com ênfase no sinal do radical livre orgânico, de amostras de um Neossolo Litólico distrófico típico (RLd) e de um Cambissolo Húmico alumínico típico ( $\mathrm{CHa}$ ) da região da Serra Gaúcha. 
(Figura 2). Estes resultados diferem dos obtidos por Silveira et al. (2006) que, ao trabalhar com dois latossolos do Estado de São Paulo, observaram que a maior parte do cobre estava ligado às frações residual e óxidos de Ferro; os resultados deste trabalho diferem, também, dos resultados de Moreira (2003), que encontrou maior quantidade de cobre na fração residual de um Latossolo Vermelho, seguida da fração óxidos e da orgânica. Deve-se considerar que os solos estudados por esses autores, quando comparados aos solos deste trabalho, possuíam metade do teor de MO, teores de argila superiores, altos teores de óxidos e teores bem inferiores de cobre total.

Grande parte do cobre, dos solos estudados, foi introduzida no sistema pela aplicação de produtos fitossanitários, e está predominantemente ligada à fração orgânica, o que está de acordo com McLaren \& Crawford (1973), que descreveram a alta afinidade do cobre por esta fração.
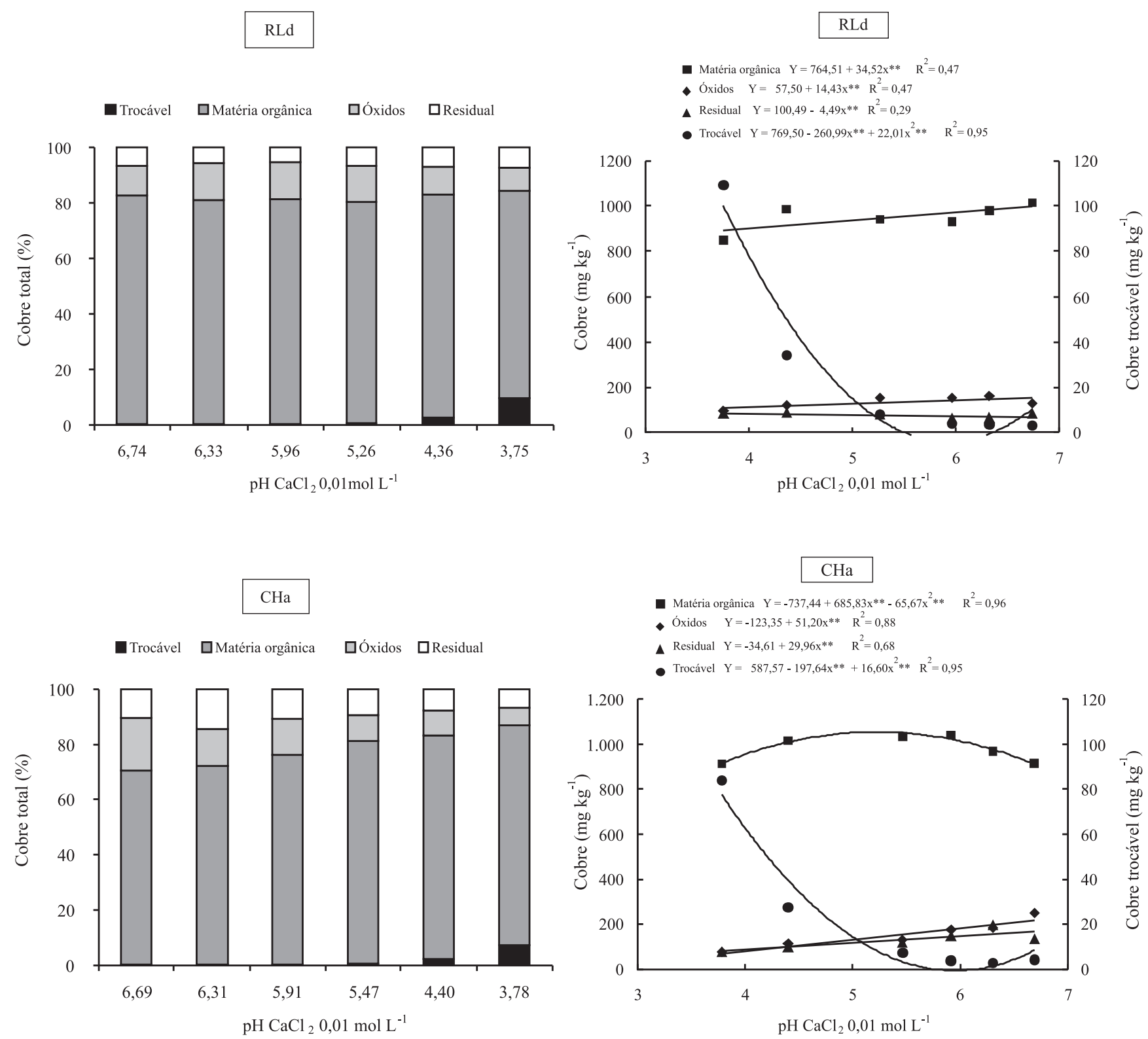

Figura 2. Distribuição porcentual e teores de cobre ligado às frações trocável, matéria orgânica, óxidos e residual e respectivos teores, em função do pH, em um Neossolo Litólico distrófico típico (RLd) e em um Cambissolo Húmico alumínico típico (CHa) da região da Serra Gaúcha. 
Com a redução do $\mathrm{pH}$ dos solos, houve pequeno aumento do cobre ligado à fração orgânica do $\mathrm{CHa}$, com proporcional redução do cobre ligado à fração óxidos, o que também foi observado por Alva et al. (2000).

A fração do cobre ligada aos óxidos representou de 7 a $20 \%$ do cobre total, enquanto a fração residual representou menos que $10 \%$. Por sua vez, a fração trocável representou, em média, menos que 1\% do cobre total. Esses resultados são semelhantes aos obtidos por Sposito et al. (1982), que obtiveram valores de cobre associados à fração solúvel + trocável inferiores a $4 \%$ do cobre total, em solos de zona árida. Bradley \& Cox (1987) encontraram entre 0,2 e 10\% (média de 1,5\%) do cobre total associado à fração trocável.

A cama-de-frango, por conter produtos biocidas que são adicionados à alimentação das aves, em geral, apresenta elevados teores de $\mathrm{Cu}, \mathrm{Zn}$ e $\mathrm{As}$ (Sims, 1995). O teor de cobre contido na cama-defrango, utilizada neste trabalho $\left(518 \mathrm{mg} \mathrm{kg}^{-1}\right)$, é inferior ao observado por Moore et al. (1998), que era de 748.

No experimento de adição de cama-de-frango, tanto no RLd quanto no $\mathrm{CHa}$, a maior proporção de cobre (68 e 85\%) ficou ligada à fração orgânica (Figura 3). Han et al. (2000) também verificaram
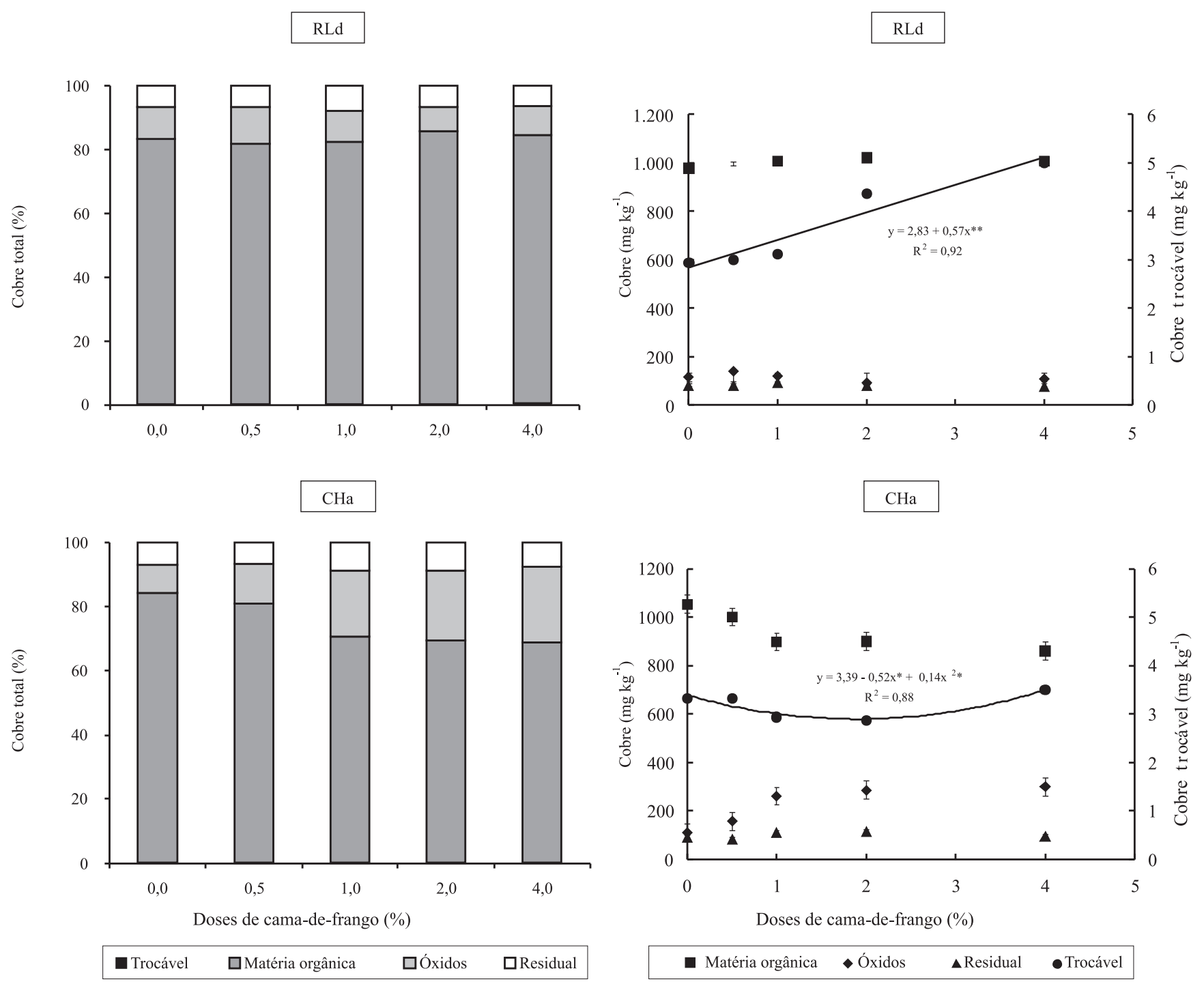

Figura 3. Distribuição porcentual e teores de cobre ligado às frações trocável, matéria orgânica, óxidos e residual e respectivos teores, em função dos teores de matéria orgânica (após adição de cama-de-frango), em um Neossolo Litólico distrófico típico (RLd) e em um Cambissolo Húmico alumínico típico (CHa) da região da Serra Gaúcha. 
que o cobre se encontrava, na grande maioria das vezes, associado à fração orgânica, em solos que receberam cama-de-frango por mais de 25 anos. A fração de cobre ligada aos óxidos representou de 8 a $24 \%$ do cobre total, a fração residual representou menos que $10 \%$ do cobre total, e a fração trocável representou, em média, menos que $1 \%$ do cobre total (Figura 3). Estes resultados seguem a mesma tendência dos obtidos por Sposito et al. (1982) e por Bradley \& Cox (1987).

Os teores de cobre, nas diferentes frações, não foram afetados significativamente pela aplicação de cama-de-frango aos solos (Figura 3), com exceção desses teores na fração trocável, que no solo RLd aumentaram de forma linear e no $\mathrm{CHa}$ aumentaram seguindo modelo quadrático, com o aumento das doses de cama-de-frango. Esse comportamento pode ser explicado pelo aporte, ao solo, do cobre da cama-de-frango. Assim, para as frações de cobre ligadas à matéria orgânica e aos óxidos, a cama-de-frango não teve influência nos altos teores de cobre observados, enquanto para a fração trocável, em que os valores extraídos são mais baixos, as doses aplicadas contribuíram com adições significativas de cobre. Embora haja alta afinidade de ligação do cobre com a MO, a falta de relação significativa entre seus teores no solo também foi observada por Brun et al. (1998).

Os efeitos similares, observados nos dois solos, em relação à variação do $\mathrm{pH}$ do solo e à adição de cama-de-frango, provavelmente estão relacionados às características físico-químicas similares desses solos, já que não apresentaram grandes diferenças quanto aos teores de óxidos e ao grau de humificação da MO, e apresentaram atributos químicos semelhantes.

\section{Conclusões}

1. A maior proporção do cobre dos solos RLd e CHa, representativos da Serra Gaúcha, está ligada à fração orgânica.

2. Com a queda do $\mathrm{pH}$, os teores e a fração cobre trocável aumentam, enquanto os teores de cobre ligados à matéria orgânica, óxidos e residual diminuem.

3. A adição de cama-de-frango não afeta a distribuição das formas de cobre nos solos, com exceção da fração trocável.

\section{Referências}

AHNSTROM, Z.S.; PARKER, D.R. Development and assessment of a sequential extraction procedure for the fractionation of soil cadmium. Soil Science Society of America Journal, v.63, p.16501658, 1999.

ALLOWAY, B.J. Heavy metals in soils. New York: Halsted Press, 1990. 339p.

ALVA, A.K.; HUANG, B.; PARAMASIVAM, S. Soil pH affects copper fractionation and phytotoxicity. Soil Science Society of America Journal, v.64, p.955-962, 2000.

BARRY, G.A.; CHUDEK, P.J.; BEST, E.K.; MOODY, P.W. Estimating sludge application rates to land based on heavy metal and phosphorus sorption characteristics of soil. Water Research, v.29, p.2031-2034, 1995.

BAYER, C.; MARTIN-NETO, L.; MIELNICZUK, J.; CERETTA, C.A. Effect of no-till cropping systems on soil organic matter in a sandy clay loam Acrisol from Southern Brazil monitored by electron spin resonance and nuclear magnetic resonance. Soil and Tillage Research, v.53, p.95-104, 2000.

BESNARD, E.; CHENU, C.; ROBERT, M. Influence of organic amendments on copper distribution among particle-size and density fractions in Champagne vineyard soil. Environmental Pollution, v.112, p.329-337, 2001.

BRADLEY, S.B.; COX, J.J. Heavy metals in the Hamps and Manifold Valleys, North Staffordshire, U.K.: partitioning of metals on floodplain soils. Science of the Total Environment, v.65, p.135-153, 1987.

BRUN, L.A.; MAILLET, J.; RICHARTE, J.; HERRMANN, P.; REMY, J.C. Relationships between extractable copper, soil properties and copper uptake by wild plants in vineyard soils. Environmental Pollution, v.102, p.151-161, 1998.

CAMARGO, O.A. de; MONIZ, A.C.; JORGE, J.A.; VALADARES, J.M.A.S. Métodos de análise química, mineralógica e física de solos do Instituto Agronômico de Campinas. Campinas: Instituto Agronômico, 1986. 94p. (IAC. Boletim técnico, 106).

CAMBRI, M.A. Calagem e formas de alumínio em três localidades sob sistema de plantio direto. 2004. 83p. Tese (Doutorado) - Escola Superior de Agricultura Luiz de Queiroz, Piracicaba.

CANDELARIA, L.M.; CHANG, A.C. Cadmium activities, solution speciation, and solid phase distribution of $\mathrm{Cd}$ in cadmium nitrate and sewage sludge-treated soil systems. Soil Science, v.162, p.722732, 1997.

CASAGRANDE, J.C.; JORDÃO, C.B.; ALLEONI, L.R.F.; CAMARGO, O.A. de. Dessorção de cobre em solo com carga variável. Scientia Agricola, v.61, p.196-202, 2004.

DELUISA, A.; GIANDON, P.; AICHNER, M.; BORTOLAMI, P.; BRUNA, L.; LUPETTI, A.; NARDELLI, F.; STRINGARI, G. Copper pollution in Italian vineyard soils. Communications in Soil Science and Plant Analysis, v.27, p.1537-1548, 1996.

ESTADOS UNIDOS. Environmental Protection Agency. Method 3052: microwave assisted acid digestion of siliceous and organically based matrices. Washington, 1996. 1 CD-ROM. 
FLORES VÉLEZ, L.M.; DUCAROIR, J.; JAUNET, A.M.; ROBERT, M. Study of the distribution of copper in an acid sandy vineyard soil by three different methods. European Journal of Soil Science, v.47, p.523-532, 1996.

HAN, F.X.; KINGERY, W.L.; SELIM, H.M.; GERARD, P.D. Accumulation of heavy metals in a long-term poultry waste-amended soil. Soil Science, v.165, p.260-268, 2000.

KABATA-PENDIAS, A.; PENDIAS, H. Trace elements in soils and plants. Boca Raton: CRC Press, 1987. 315p.

MARTIN-NETO, L.; ROSELL, R.; SPOSITO, G. Correlation of spectroscopic indicators of humification with mean annual rainfall along a temperate grassland climosequence. Geoderma, v.81, p.305311, 1998

McLAREN, R.G.; CRAWFORD, D.V. Studies on soil copper. I. The fractionation of copper in soils. Journal of Soil Science, v.24, p.172-181, 1973.

MOORE, P.A.; DANIEL, T.C.; GILMOUR, J.T.; SHREVE, B.R.; EDWARDS, D.R.; WOOD, B.H. Decreasing metal runoff from poultry litter with aluminum sulfate. Journal of Environmental Quality, v.27, p.92-99, 1998.

MOREIRA, S.G. Formas químicas no solo e disponibilidade de micronutrientes à soja em sistema de semeadura direta. 2003. 149p. Tese (Doutorado) - Escola Superior de Agricultura Luiz de Queiroz, Piracicaba.

NOGUEIROL, R.C.; NACHTIGALL, G.R.; ALLEONI, L.R.F. Distribuição dos teores de cobre em profundidade em diferentes tipos de solos com vinhedos no Rio Grande do Sul. In: CONGRESSO BRASILEIRO DE CIÊNCIA DO SOLO, 30., 2005, Recife. Anais. Recife: SBCS, 2005. 1 CD-ROM.

NOVOTNY, E.H. Estudos espectroscópicos e cromatográficos de substâncias húmicas do solo sob diferentes sistemas de preparo. 2002. 215p. Tese (Doutorado) - Universidade de São Paulo, São Carlos.
NOVOTNY, E.H.; MARTIN-NETO, L. Effects of humidity and metal ions on the free radicals analysis of peat humus. Geoderma, v.106, p.305-317, 2002.

OLIVEIRA, K.W.; MELO, W.J. de; PEREIRA, G.T.; MELO, V.P. de; MELO, G.M.P. de. Metais pesados em latossolos tratados com biossólido e cultivados com milho em experimento de longa duração. Scientia Agricola, v.62, p.381-388, 2005.

SCHWERTMANN, U. Differenzierung der Eisenoxide des Bodens durch Extraktion mit Ammoniumoxalat-Lösung. Zeitschrift für Pflanzenernährung und Bodenkunde, v.105, p.194-202, 1964.

SHANNON, R.D.; WHITE, J.R. The selectivity of a sequential extraction procedure for the determination of iron oxyhydroxides and iron sulfites in lake sediments. Biogeochemistry, v.14, p.193208, 1991.

SHUMAN, L.M. Effect of liming on the distribution of manganese, copper, iron, and zinc among soil fractions. Soil Science Society of America Journal, v.50, p.1236-1240, 1986.

SILVEIRA, M.L.; ALLEONI, L.R.F.; O'CONNOR, G.A.; CHANG, A.C. Heavy metal sequential extraction methods - a modification for tropical soils. Chemosphere, v.64, p.1929-1938, 2006.

SIMS, J.T. Characteristics of animal wastes and waste amended soils: an overview of the agricultural and environmental issues. In: STEELE, K. (Ed.). Animal waste and the land-water interface. Boca Raton: CRC Press, 1995. p.1-14.

SPOSITO, G.; LUND, L.J.; CHANG, A.C. Trace-metal chemistry in arid-zone field soils amended with sewage-sludge. I. Fractionation of $\mathrm{Ni}, \mathrm{Cu}, \mathrm{Zn}, \mathrm{Cd}$, and $\mathrm{Pb}$ in solid-phases. Soil Science Society of America Journal, v.46, p.260-264, 1982.

TEIXEIRA, S.T.; MELO, W.J.; SILVA, É.T. Metais pesados em solo degradado tratado com lodo de estação de tratamento de água. Scientia Agricola, v.62, p.498-501, 2005.

$\overline{\text { Recebido em } 28 \text { de junho de } 2006 \text { e aprovado em } 29 \text { de dezembro de } 2006}$ 